\title{
Agrotóxicos no Brasil: Uma Visão Relacional a Partir da Articulação Freire-CTS ${ }^{1}$
}

\section{Pesticides in Brazil: a Relational View Based on Freire-STS Articulation}

\author{
Polliane Santos de Sousa ${ }^{(1)}$ Brasil \\ Ana Paula Gorri ${ }^{(1)}$ Brasil
}

Na pesquisa em Educação em Ciências o tema Agrotóxicos é considerado promissor para a discussão de aspectos sociais da Ciência e da Tecnologia. Por seu caráter controverso e imbricado em uma malha sociocultural, a sua discussão envolve aspectos de ordem conceitual, política, econômica, social, de saúde pública e ambiental que necessitam ser considerados ao abordá-lo em sala de aula. Nesse sentido, o presente trabalho discute algumas das dimensões presentes no uso de agrotóxicos no contexto brasileiro, visando fornecer subsídios teóricos para a discussão do tema numa perspectiva mais ampla em sala de aula. Especificamente, pautado na articulação dos pressupostos do movimento CTS e da perspectiva educacional freireana, são discutidos alguns dos aspectos envolvidos neste tema mediante a construção de uma rede de relações, baseada na proposta da Rede Temática, tendo como referência dimensões relacionadas com a economia; meio ambiente e saúde pública; e políticas públicas e participação social.

Palavras-chave: Educação em Ciências; Agrotóxicos; Movimento CTS; Abordagem Temática Freireana.

In Science Education research, pesticides are considered promising for a discussion on the social aspects of science and technology. Considered to be a controversial subject embedded in a sociocultural network, discussing it involves not only conceptual, political, economical and social aspects, but alsopublic and environmental health issues that need to be considered when addressing it in the classroom. Thus, this work discusses some of the dimensions present in the use of pesticides in the Brazilian context, providing theoretical subsidies for the discussion of the theme in the classroom. On the basis of the articulation between the Science, Technology and Society (STS) movement and the Freirean educational perspective, we discuss some of the aspects around the subject through the definition of a web of relationships based on the Thematic Network proposal, explaining dimensions related to the economy, to the environment and public health, as well as to public policies and social participation.

1 Uma versão preliminar deste estudo foi apresentada na I Semana do Programa de Pós-Graduação em Educação Científica e Tecnológica: 15 anos contribuindo para a evolução da pesquisa e ensino, 2017. Apoio: Capes. 
Keywords: Science Education; Pesticides; STS movement; Paulo Freire's Thematic Approach.

\section{Introdução}

Desde seu primórdio, a humanidade tem a agricultura como uma das principais formas de se relacionar com a natureza e garantir a sua sobrevivência (Calvão, 2017). Como colocam Bianchini e Medaets (2013), os diferentes modos de desenvolver a agricultura apresentam conhecimentos e fazeres específicos de cada época, com diferentes intensidades e impactos no ambiente.

Gradativamente, com especial influência da revolução industrial, a compreensão e a prática de uma agricultura pautada em um sistema de rotação de plantio, na qual pecuária e lavoura eram trabalhadas de maneira articulada, foi sendo substituída por uma lógica de produção pautada na ideia de um campo mecanizado, centrado na monocultura e com intensivo uso de insumos agrícolas. Segundo Bianchini e Medaets (2013), foi no final do século XIX e início do XX, devido ao desenvolvimento da agricultura nos Estados Unidos, pautado no processo intensivo de colonização e na visão da agricultura como negócio, que o plantio em monocultura foi instituído e implantado em diversos lugares do mundo, principalmente em países compreendidos como em "desenvolvimento". Para os autores, os países considerados "subdesenvolvidos" foram contemplados com políticas agrícolas oriundas dos Estados Unidos e Europa. Tais políticas foram parte do movimento denominado de Revolução Verde.

Os conhecimentos e aparatos tecnológicos pertencentes à lógica da Revolução Verde, dentre eles a manipulação genética e agroquímicos, possibilitaram e possibilitam o cultivo de inúmeros alimentos, independente das condições climáticas e do espaço local. Originando, na maioria dos casos, uma maior produtividade de alimentos.

No entanto, existem controvérsias acerca dos benefícios de tais práticas agrícolas. No Brasil, por exemplo, o uso de agrotóxicos tem sido objeto de intensos debates nas últimas décadas, de modo que abordar a utilização de agrotóxicos no contexto brasileiro envolve considerar pelo menos dois posicionamentos. $\mathrm{O}$ primeiro diz respeito à lógica econômica, segundo a qual o uso dos agrotóxicos é primordial para a maioria dos sistemas produtivos rurais brasileiros, sendo considerado em 2009 o maior consumidor de agrotóxicos do mundo. Segundo Veiga (2007), sob este prisma, as práticas agrícolas convencionais aumentam a produtividade e, consequentemente, reduzem as demandas por recursos naturais e tecnológicos, aumentando assim a oferta de produtos e diminuindo os custos para os consumidores. Acredita-se que por meio de tal sistema de produção de alimentos se permite maior acesso da população aos bens produzidos, elevando, deste modo, as condições de saúde, com o aumento na quantidade/qualidade dos alimentos consumidos.

O segundo posicionamento, entretanto, apresenta os argumentos que advertem para os prejuízos, em diferentes esferas do ecossistema, do uso de agrotóxicos. Os quais abarcam, por exemplo, a marginalização da agricultura familiar, a perda de biodiversidade, 
a contaminação ambiental e diferentes tipos de intoxicação, como evidencia o "Dossiê ABRASCO: um alerta sobre os impactos dos agrotóxicos na saúde" (Carneiro, Augusto, Rigotto, Friedrich \& Búrigo, 2015).

Neste contexto, compreender as problemáticas envolvidas na produção de alimentos no Brasil perpassa a formação de sujeitos detentores de diferentes conhecimentos e posicionamentos críticos perante tal realidade. Contudo, uma educação nessa perspectiva também envolve discutir a formação de professores, afinal, tal como argumentado por Fernandes e Stuani (2015), o caráter controverso da temática dos agrotóxicos pode ser um indicativo das dificuldades enfrentadas para a sua abordagem sala de aula. Segundo Reis (2004), por exemplo, entre as dificuldades encontradas por professores para a abordagem de temas controversos em sala de aula, pode-se mencionar a necessidade de maior conhecimento sobre a natureza da ciência e sobre os aspectos sociológicos, políticos, éticos e econômicos dos assuntos em questão.

No que concerne ao papel da Educação em Ciências nesse processo, embora o tema "Agrotóxicos" seja considerado promissor para a discussão de aspectos sociais da ciência e tecnologia em sala de aula (Lopes, \& Carvalho, 2012; Santos, \& Mortimer, 2002), segundo Fernandes e Stuani (2015) a temática ainda é pouco explorada. Em relação aos livros didáticos, Fernandes e Stuani (2015) apontam que das cinco coleções de livros didáticos de Química do Ensino Médio aprovadas pelo Plano Nacional do Livro Didático em 2012, por exemplo, apenas uma delas abordava de maneira explícita esse tema. Moraes, Trajano, Mafra e Messede (2011), ao apresentarem uma revisão sobre a abordagem de tal temática em pesquisas da área de Ensino de Ciências, apontam que mesmo quando abordada como uma temática social - que ultrapassa os limites do individual e se coloca como um problema ambiental e de saúde pública - a discussão se limita ao tratamento de seus aspectos químicos e ambientais.

Segundo Takahashi, Martins e Quadros (2008), majoritariamente, as pesquisas da área inserem a temática agrotóxico no ensino de Química ao abordarem conceitos científicos específicos. Outra abordagem comumente utilizada são as implicações dos agrotóxicos no organismo humano (Cavalcanti, Freitas, Melo, \& Freitas, 2010).

Dessa forma, há indicativos de que, quando realizada, a abordagem do tema agrotóxicos na Educação em Ciências ocorre de maneira fragmentada, descolando tal temática do contexto social e histórico, restringindo-se às abordagens conceituais e científicas. Ademais, ainda que tais pesquisas discutam elementos relacionados com os conhecimentos, práticas e impactos negativos da agricultura convencional, não apontam uma alternativa para tais realidades. Isto é, há certa predominância da "história e saberes únicos”, reforçando as práticas agrícolas pautadas na Revolução Verde como único conhecimento e forma do ser humano se relacionar com o mundo e obter o próprio alimento, não tendo opções de, por exemplo, questionar e propor outras opções para os atuais problemas relacionados com a produção de alimentos.

Nesse contexto, sem a pretensão de esgotar o tema, o presente trabalho tem por objetivo abordar o uso de agrotóxicos no Brasil visando fornecer subsídios teóricos para 
a discussão do tema numa perspectiva mais ampla em sala de aula e que considere, na medida do possível, outros caminhos para a produção de alimentos, em especial, outros olhares sobre o papel dos agrotóxicos no contexto brasileiro, a fim de contribuir com as atuais problemáticas da produção convencional de alimentos. Destaca-se a relevância deste tema no cenário nacional, que tem suscitado inúmeros debates e posicionamentos controversos, especialmente após a aprovação do registro, pelo Ministério da Agricultura, de 211 agrotóxicos somente no primeiro semestre de 2019 (Reuters, 2019) e com a divulgação do mapa dos agrotóxicos presentes na rede de abastecimento de água de diversos municípios em todo o Brasil (Aranha, \& Rocha, 2019).

\section{Olhares sobre a produção de alimentos e o uso de agrotóxicos no Brasil}

A discussão sobre o desenrolar da agricultura brasileira, é permeada por processos colonizatórios que reverberam até hoje (Lerrer, 2019). Prado Junior (1949), com base analítica na representação conceitual denominada por ele de "sentido da colonização", elenca quatro principais pilares, para a realidade contemporânea do Brasil, que se relacionam diretamente com o desenrolar da agricultura. São estes: o grande latifúndio; a monocultura; o trabalho escravo; e a produção dos gêneros primários voltados ao mercado externo (Prado Júnior, 1949).

Por exemplo, ao considerarmos a relação entre a expulsão dos indígenas de seus territórios e o avanço da monocultura, temos os primórdios do cultivo em larga escala da cana-de-açúcar. Esta, sendo uma das primeiras atividades econômicas no Brasil, demandou, logo no início do processo colonizatório, a destinação de amplas áreas territoriais para o seu cultivo - haja vista que o retorno econômico só ocorre se plantada em grandes territórios (Prado Júnior, 1949).

Inúmeros relatos sinalizam que, no início da colonização, existia abundância de alimentos em todos os povoados. Além disso, a base alimentar dos povos originários contava com pescado, marisco e criação de animais (Hue, 2006). Os modos de produção de alimentos de tais povos, modos estes ainda presentes na agricultura de etnias tradicionais (Felipim, 2001), apresentam saberes e fazeres semelhantes aos praticados dentro do sistema de plantação denominado de plantation - oriundo da Primeira Revolução Agrícola, ocorrida na Europa após o século XVI. Segundo Bianchini e Meadaets (2013), tais práticas envolviam a integração da lavoura com a pecuária, um rico sistema de rotação de plantação, tendo como destaque as gramíneas leguminosas e plantas com tubérculos, utilizando-se de equipamentos de tração animal no plantio.

De acordo com Bianchini e Meadaets (2013), foi com o surgimento da Segunda Revolução Agrícola, dos tempos modernos, que a agricultura tradicional passa a ser substituída pela agricultura intensiva em insumos, denominada de agricultura convencional ou moderna. Os autores destacam que com essa nova agricultura, ocorreu, além da extrema dependência da mesma em relação à indústria, uma relativa homogeneização das agriculturas mundiais e impactos significativos ao meio ambiente. 
As origens de tais práticas teriam vindo de experiências com o cultivo de cereais em 1850, ao passo que as mesmas mostraram que era possível o plantio por meio da monocultura de cereais durante anos sobre o mesmo solo empregando-se "apenas" fertilizantes químicos. Assim, a Segunda Revolução Agrícola, apoiada por um conjunto de incentivos de políticas agrícolas nos Estados Unidos e Europa, ficou conhecida internacionalmente por "Revolução Verde" (Bianchini, \& Meadaets, 2013).

Foi na década de 60 do século XX que o movimento denominado de Revolução Verde veio com a bandeira de diminuir o sofrimento do sujeito do campo, juntamente com a redução da fome em países considerados com “déficit de alimentos". Neste contexto, é importante lembrar que tal movimento teve como um dos financiadores o grupo Rockefeller, sendo este o mesmo que se fortaleceu devido ao aumento das vendas de pacotes de insumos agrícolas para países em processo de "desenvolvimento" - dentre estes o Brasil, Índia e México. Assim, as inovações tecnológicas na agricultura oriundas de tal movimento possibilitaram a obtenção de maior produtividade através do desenvolvimento de pesquisas em melhoramentos de sementes, fertilização de solo, utilização de agroquímicos e mecanização do campo (Calvão, 2017).

No contexto brasileiro, entre os conhecimentos e práticas da agricultura convencional empregados destacam-se, devido aos seus impactos ao meio, a larga utilização de agrotóxicos, fertilizantes e sementes transgênicas no processo de produção de alimentos. Embora o início da implantação de novas técnicas agrícolas no Brasil tenha ocorrido no período pós Segunda Guerra Mundial - muitas delas frutos de estudos e artefatos oriundos da indústria bélica - foi apenas nas décadas de 60 e 70 que ocorreu o aumento significativo da produção agrícola, juntamente com inúmeros impactos negativos em diferentes esferas do meio, causados por tal modo de produção (Possenti, Tozetto, Bettiato, \& Szepanhuk, 2007) .

O desejo de controle sobre as sementes, a fim de que as mesmas fossem capazes de se desenvolverem, com melhor custo econômico, em qualquer tipo de condição ambiental e para que fossem resistentes aos agroquímicos utilizados para afastar ou matar pragas e doenças, impulsionou tanto o considerável aumento de alimentos destinados à exportação quanto os impactos negativos relacionados, principalmente, aos riscos inerentes ao monopólio da biodiversidade, com problemas sociais e do meio ambiente e a saúde pública (Carneiro et al., 2015).

Além de toda problemática relacionada com a dependência de um conhecimento importado para se produzir alimentos e, consequentemente, a morte da semente crioula, dos saberes e práticas locais, tal monopólio, juntamente com as tecnologias relacionadas à mecanização do campo, fizeram com que houvesse uma redução significativa do número de trabalhadores na rotina do campo, gerando o conhecido êxodo - que trouxe em seu bojo o desemprego, violência e pobreza. Outra problemática está na realidade de muitos dos agricultores que continuaram no campo e que não conseguiram se adaptar às novas demandas, não atingindo a produtividade necessária para competir com as grandes empresas agrícolas, e se endividaram devido aos empréstimos bancários para a 
mecanização das atividades.

Para Romeiro (1996), ao contrário de outros países que tiveram a adoção e/ou imposição dos princípios da Revolução Verde, o Brasil possuía uma capacidade científica e técnica capaz de desenvolver sua própria agricultura, sendo estas estruturadas de acordo com suas especificidades naturais e de recursos humanos. No entanto, devido à sua herança colonial e escravocrata, a elite brasileira desenvolveu seu modo de produzir alimentos, ao longo do tempo, pautados em conhecimentos que atendem diretamente aos seus interesses econômicos. O autor pontua que, o foco na lógica voltada à monocultura de exportação, fez com que a produção de alimentos para o mercado interno fosse deixada para segundo plano. Assim, ao se ter o maior território ocupado por monocultura, gera-se uma escassez relativa de alimentos, para consumo interno, num país com a maior área agrícola do planeta.

\section{Abordagem CTS e a perspectiva freireana}

No período pré Segunda Guerra Mundial, a percepção da Ciência e da Tecnologia como instrumentos a serviço do desenvolvimento econômico e social ganha força (Schwartzman, 1989). Tal compreensão permanece no período pós-guerra traduzida em políticas de financiamento de Ciência e Tecnologia (CT), reforçando um modelo linear de desenvolvimento, segundo o qual mais ciência acarreta mais tecnologia e, consequentemente, mais riqueza e bem-estar social (Auler, 2002).

Apesar do cenário otimista, uma sucessão de desastres relacionados com CT, ocorridos especialmente no final da década de 50, impulsionaram a necessidade de revisar a política científica e tecnológica e a própria concepção de Ciência e Tecnologia, desencadeando reivindicações de mecanismos democráticos de controle da sociedade sobre as atividades científico-tecnológicas (Bazzo, Linsingen, \& Pereira, 2003).

Nesse contexto, surge em meados do século XX, o movimento Ciência, Tecnologia e Sociedade (CTS), abordando o fenômeno científico e tecnológico como processo social, discutindo as consequências ambientais e sociais da pesquisa em CT e buscando novas maneiras de compreender o seu desenvolvimento (Strieder, 2012; Linsingen, 2007).

Consequentemente, o debate desencadeado pelo movimento CTS também produziu desdobramentos em outras áreas do conhecimento. Segundo Santos (2011), o enfoque CTS constitui um movimento social mais amplo que repercutiu no cenário educacional, contribuindo para o desenvolvimento de uma educação científica voltada para a formação cidadã, preocupada com o desenvolvimento de valores e com a capacidade de tomada de decisão sobre questões científicas e tecnológicas.

No contexto educacional brasileiro essas discussões ganharam destaque a partir da década de 90, originando, desde então, uma diversidade de abordagens que abarcam desde a discussão das interações CTS como fator motivacional até a ênfase na discussão destas interações em detrimento do conhecimento científico envolvido (Auler, 2002).

A incorporação das discussões do movimento CTS no cenário educacional brasileiro também produziu novas leituras e articulações entre diferentes enfoques 
e linhas teóricas (Linsingen, 2007). Entre elas, destaca-se as articulações entre o movimento CTS e os pressupostos educacionais de Paulo Freire, perspectiva adotada no presente trabalho. Segundo Nascimento e Linsingen (2006) essa articulação proporciona tanto uma base teórica educacional sólida para abordagens CTS quanto oportuniza a abordagem de temas atuais relacionados com CT em abordagens freireanas.

Destaca-se que, para o educador brasileiro Paulo Freire a educação, por seu caráter político, é uma forma de intervenção no mundo. Isto é, o processo educativo envolve a construção do conhecimento que, por ser desenvolvida por sujeitos históricoculturais e não por objetos, abarca a problematização das relações homens-mundo com vistas à superação das contradições sociais vivenciadas pelos indivíduos (Freire, 1983). Nessa perspectiva, o espaço educativo constitui lugar em que, coletivamente, há a problematização dos conteúdos na defrontação com a realidade concreta e social dos indivíduos.

Sob este prisma, Freire (2011) fornece encaminhamentos para o desenvolvimento de processos educativos estruturados a partir de Temas Geradores, obtidos mediante o processo de Investigação Temática eintrinsecamente relacionados com as situações-limite vivenciadas pelos educandos, a partir dos quais são selecionados os conteúdos de ensino ${ }^{2}$.

Considerando, entre outros aspectos, que para Freire a educação relacionase com o desvelamento da realidade com vistas a sua transformação, Auler (2007) argumenta que, diante da dinâmica social contemporânea, uma leitura do mundo não pode prescindir da compreensão crítica das interações CTS. Nesse sentido, Auler (2007) propõe a abordagem de temas em sala de aula sensíveis ao entorno, tal como preconizado por Freire, e marcados pela componente científico-tecnológica, em consonância com o movimento CTS.

Contudo, ao abordar a democratização dos processos de tomada de decisão sobre questões envolvendo a tônica científica e tecnológica, Auler (2007) destaca que os pressupostos freireanos estão enraizados em países da América Latina e África, os quais possuem um histórico de passado colonial que se manifesta na ausência de participação da sociedade em processos decisórios. Dessa forma, Auler (2011) sinaliza que, embora nos encaminhamentos CTS a utilização de práticas educativas que incentivam a tomada de decisão tem sido considerada potencializadora da participação, há indicativos de que os critérios balizadores da denominada tomada de decisão fundamentada encontram-se restritos ao campo científico e tecnológico, reforçando o modelo de decisões tecnocráticas e silenciando outras dimensões. Segundo o autor:

Processos de tomada de decisão têm ocorrido em configurações curriculares organizadas em torno de temas, problemas (temas controversos, temas sociais,

2 Em síntese, mediante o desenvolvimento de algumas etapas de investigação da realidade da comunidade escolar e do seu pensar sobre ela, são identificadas situações-limite, situações de injustiça social percebidas de maneira acrítica pelos sujeitos, a partir das quais, mediante uma análise relacional, são selecionados os conhecimentos científicos necessários para melhor compreendê-las. Maiores detalhes sobre os desdobramentos do referencial freireano no ensino de Ciências podem ser encontrados na literatura pertinente, porém, pode-se destacar os trabalhos de Delizoicov (1991), Angotti (1991), Pernambuco (1994) e Silva (2004). 
temas sociocientíficos). Esses problemas/temas contemporâneos são complexos, não compreensíveis, abarcáveis, apenas pelo olhar da CT (Auler, 2011, p. 82).

Portanto, Auler (2011) adverte que reduzir a discussão de temas desta natureza a dimensão científica compromete a educação para participação desejável no contexto educacional brasileiro.

\section{Análise relacional do tema Agrotóxicos}

Com base nos pressupostos da articulação Freire-CTS, entende-se que a discussão do uso de agrotóxicos no Brasil sob uma perspectiva mais ampla, buscando evidenciar não apenas a sua dimensão técnica, mas também social, política e ambiental, pode contribuir com a abordagem deste tema em sala de aula, amenizando a possibilidade de seguir um viés meramente tecnocrático. Ademais, tal tema, além de ser considerado promissor na discussão de aspectos da CT em sala de aula, possui um relativo grau de generalização, podendo ser explorado, com as devidas adaptações, em diferentes contextos de ensino e aprendizagem.

Para auxiliar na construção de uma visão mais ampla do tema optou-se pela construção de uma rede de relações baseada na proposta de Rede Temática de Silva (2004) para a construção de currículos escolares na perspectiva freireana.

Elaborada durante o terceiro momento ${ }^{3}$ da investigação temática sistematizada por Silva (2004) para a construção de programas escolares na perspectiva freireana, a Rede Temática pode ser compreendida como um instrumento analítico-propositivo que sintetiza as diferentes visões da realidade investigada no processo de obtenção de Temas Geradores. Nela, após o reconhecimento do Tema Gerador, mediante identificação e problematização das situações-limite vivenciadas pela comunidade escolar, é realizada a análise relacional e contextualizada da realidade local em diferentes dimensões, buscando compreendê-la enquanto construção histórica.

Segundo Silva (2004), partindo do local para o macroestrutural, a Rede Temática tem como ponto de partida as falas significativas da comunidade, obtidas durante a investigação, que expressam concepções de mundo e contradições sociais experienciadas pelos sujeitos. A partir da percepção da comunidade é realizada pela equipe de investigadores/educadores uma análise dessa realidade desde a dimensão micro à macrossocial, explicitando as relações socioculturais e socioeconômicas presentes nos diferentes níveis. No centro da rede encontra-se o Tema Gerador, enquanto síntese da problemática local sob a perspectiva da comunidade, e no topo o Contratema, que constitui um contraponto analítico que se opõe ao Tema Gerador, isto é "uma

\footnotetext{
3 Pautado no referencial freireano, Silva (2004) sistematiza a construção de currículos escolares críticos em cinco momentos organizacionais, quais sejam: i) Desvelamento do real pedagógico a partir das necessidades imanentes da prática; ii) Resgate de falas significativas constituindo sentido à prática: elegendo temas/contratemas geradores; iii) Contextualização e percurso do diálogo entre falas e concepções da realidade local: rede temática e questões geradoras; iv) Planejamento e organização pedagógica da prática crítica; v) Reorganização coletiva da escola a partir do fazer pedagógico.
} 
bússola norteadora da síntese analítica/propositiva, desveladora da realidade local que se pretende construir com os educandos, na perspectiva da intervenção na realidade imediata" (Silva, 2004, p. 213).

Nesse sentido, a rede proporciona uma visão ampla do tema a ser abordado na sala de aula acerca das diferentes leituras da realidade, contribuindo com o delineamento de critérios ético-críticos e político-epistemológicos para a construção das programações (Silva, 2004). Segundo o autor:

Procura-se, assim, colocar o acervo de conhecimentos sistematizados das áreas à disposição dos sujeitos, e não estes subordinados a conhecimentos preestabelecidos e idealizados por especialistas socioculturais orgânicos aos interesses das elites econômicas. É nesse sentido que se enfatiza a necessidade de selecionar conhecimentos requeridos pela problematização em curso e de priorizar não apenas produtos do empreendimento científico, mas seus processos de construção (Silva, 2007, p. 17).

Destaca-se que, como na presente pesquisa não foi realizado um processo de Investigação Temática, a rede de relações sobre o uso de agrotóxicos no Brasil aqui apresentada será composta de alguns aspectos da visão macroestrutural, no que concerne ao cenário nacional, oriundos de produções acadêmicas sobre o tema que constituem fatores importantes para a sua abordagem. Além disso, deve-se salientar que temas desta amplitude necessitam de uma abordagem interdisciplinar. Nesse sentido, tratando-se da sua abordagem no Ensino de Ciências não defendemos a ideia do professor polivalente, mas a necessidade de construir a interdisciplinaridade mediante "a colaboração integrada de diferentes especialistas que trazem a sua contribuição para a análise de determinado tema." (Delizoicov, \& Zanetic, 1993, p.13). Sendo assim, a partir da articulação entre os referenciais do enfoque CTS e freireano, também se pretende sinalizar para a relevância de abordar a temática agrotóxicos buscando-se amenizar a histórica separação entre as denominadas ciências naturais e ciências humanas presente nos trabalhos pautados nas relações CTS, tal como identificado por Auler, Dalmolin e Fenalti (2009).

\section{Construção da rede de relações}

A construção de uma Rede Temática constitui um processo de sucessivas sistematizações que ampliam o olhar sobre determinado tema do ponto de vista micro para o macroestrutural. Segundo Silva (2004), inicia-se com a análise relacional das falas da comunidade, que justificam o Tema Gerador selecionado para a construção do programa escolar, passando pela análise das articulações com aspectos da infraestrutura local e, em seguida, abarcando aspectos da organização social mais ampla que envolvem, por exemplo, as políticas públicas, os movimentos sociais, modelos socioeconômicos etc. Nesse processo, busca-se explicitar os aspectos históricos, econômicos e culturais da organização social, e as transformações espaço/temporais dela provenientes, proporcionando o distanciamento crítico e a leitura coletiva da realidade (Silva, 2007).

No presente estudo, mediante adaptações, são utilizados princípios de sistematização de uma Rede Temática na construção de uma rede de relações que 
explicite algumas das dimensões envolvidas no uso de agrotóxicos no Brasil. Destaca-se, entretanto, a relevância do desenvolvimento da Investigação Temática para a construção, por educadores, de programas escolares pautados na perspectiva freireana.

Embora a presente pesquisa não disponha de falas significativas de uma comunidade escolar específica, entende-se que as investigações presentes na literatura podem evidenciar alguns discursos comuns ao se tratar do tema, elucidando alguns dos principais aspectos envolvidos com sua abordagem no processo educativo. Por exemplo, é comum o discurso acerca da necessidade do uso de agrotóxicos apresentando uma visão fatalista acerca das possibilidades de cultivo. No estudo de Salvador, Moraes e Auler (2015), o levantamento de informações de uma comunidade escolar de JaguariRS evidenciou a dependência dos agrotóxicos por parte dos agricultores locais, que não visualizavam outras alternativas de cultivo. Percepção que, segundo Auler e Auler (2015), também abrange outros contextos escolares da região.

Entre as justificativas identificadas por Lindemann (2010), mediante entrevistas com pequenos agricultores, para o uso excessivo de agrotóxicos encontra-se a necessidade de garantir a produção e o sustento da família, assim como a viabilidade produtiva de algumas culturas e a tentativa de suprir a pouca mão-de-obra. Segundo Genovese e Pessoa (2013), "os trabalhadores rurais, pelo menos no Brasil, costumam aceitar a imposição do mercado quanto ao uso de fertilizantes e agrotóxicos para melhorar a produção da colheita" (p. 7).

Nesse contexto, constata-se que a produtividade, rentabilidade e adesão acrítica dos modelos de produção pautados na Revolução Verde constituem aspectos bastante presentes nas investigações. Assim, considera-se que a dimensão econômica da temática é um elemento importante na sua abordagem.

Oestudo deSalvador, Moraes e Auler (2015) também evidencia o desconhecimento de uma comunidade escolar sobre os riscos do uso dos agrotóxicos para a saúde e o meio ambiente. Sobre o desenvolvimento desta pesquisa, Auler e Auler (2015) destacam, ainda, que também houveram relatos de intoxicação por agrotóxicos e contaminação do meio ambiente apresentados pelas comunidades locais. Tais aspectos encontram ênfase no relato do ex-trabalhador rural entrevistado por Genovese e Pessoa (2013), assim como na pesquisa realizada por Lindemann (2010). Nesse sentido, entende-se que elementos relacionados com meio ambiente e saúde pública estão intrinsecamente relacionados com a temática dos agrotóxicos.

Também são sinalizadas em tais pesquisas a necessidade de ações, não apenas no campo educacional, que permitam refletir sobre os modos de produção adotados e reduzir o uso excessivo de agrotóxicos nas plantações. A pesquisa de Lindemann (2010), por exemplo, menciona as contribuições da abordagem de práticas agroecológicas para a formação técnica de estudantes de assentamentos do Movimento Sem Terra. Segundo relatos de agricultores, a experiência com práticas agroecológicas nos assentamentos sinaliza para técnicas de cultivo também possíveis. Auler e Auler (2015) também discutem a relevância de resgatar conhecimentos e práticas tradicionais, segundo os 
autores: "Está em curso, o que também deve estar ocorrendo em outros campos, um processo de perda irreversível, pela ação devastadora do atual modelo econômico, de culturas, práticas e conhecimentos, no campo das práticas agrícolas, com a morte dos pais e avós." (p. 37). Nesse sentido, também se considera relevante abordar a discussão no âmbito das políticas públicas e participação social relacionadas com a perpetuação ou alteração das práticas de cultivo convencionais.

Com base em tais considerações, a rede de relações apresentada no presente trabalho tem como ponto de partida aspectos relacionados com: economia; meio ambiente e saúde pública; e políticas públicas e participação social, os quais serão discutidos a seguir, tendo em vista uma compreensão mais ampla do tema. Destaca-se que os trabalhos mencionados nesta seção representam apenas algumas das investigações que evidenciam elementos da realidade e do pensar de comunidades relacionados com o uso de agrotóxicos. Neles encontram-se dimensões essenciais para a abordagem do tema, também presentes em outras pesquisas da área.

\section{a) Dimensão econômica}

Durante as décadas de 60 e 70 ocorreu a expansão do cultivo agrícola com base na Revolução Verde em vários países pelo mundo. Porém, somente após a década de 90 que, devido a política econômica brasileira ter se encaminhado para uma estrutura neoliberalista, os produtos internos ganharam espaços fora do Brasil. Segundo Miranda, Moreira, Carvalho e Perez (2007), como uma das consequências de tal estrutura, a abertura do comércio externo, proporcionou, em 2004, resultados econômicos positivos. Em especial, as exportações agrícolas foram determinantes para esses resultados. Por exemplo,

as vendas ao exterior realizadas pelo setor de agronegócio totalizaram, em 2004, 39 bilhões de dólares, valor $27 \%$ superior ao obtido no ano anterior. Essas exportações representaram $40 \%$ do volume total exportado pelo país, contribuindo de maneira determinante para o superávit da balança comercial do país (Miranda et al., p.8, 2007).

Miranda et al. (2007) destacam que também ocorreu um significativo crescimento da quantidade de alimentos destinados para demandas internas, ainda que o acesso regular aos alimentos não atinja todos os segmentos da população.

Contudo, ao se tornar um grande exportador de commodities, a dependência do Brasil em relação a demanda externa faz prevalecer uma limitada variedade de produtos básicos para a exportação o que, consequentemente, implica nos tipos de alimentos com maior disponibilidade dentro do próprio país, tais como milho, soja em grão, cana, café, carne bovina e de frango e pasta de papel. Sobre a relação de demanda e produção, uma vez que tais produtos, em muitos casos, não são da origem local, ou necessitam que seu ciclo seja acelerado, justifica-se as inúmeras intervenções por meio de agrotóxicos e a monocultura (Watson, 2016).

Nesse sentido, essas produções tornam-se, na maioria das vezes, dependentes dos chamados "pacotes agrícolas", compostos pelas sementes transgênicas e seus respectivos 
insumos agrícolas para seu cultivo - desenvolvidos, em geral, por um monopólio empresarial.

Com os créditos de empréstimo fornecidos para os pequenos agricultores, empréstimos estes oriundos de bancos ou do próprio governo, tais instituições impõem a forma de cultivo ao alegar que o crédito de empréstimo só poderá ser efetivado mediante as notas de compras dos produtos para agricultura convencional, tal como realizado em 1965 através do Sistema Nacional de Crédito Rural (Londres, 2011). Com isso, muitos pequenos agricultores, esmagados pela instituição de tais recursos tecnológicos e científicos, entraram em endividamento e dependência de tais instituições financeiras - sendo estas umas das principais causas do êxodo rural (Lindemann, 2010).

Uma vez que tal agricultura substituiu o trabalho humano por máquinas, foram inúmeras as implicações negativas que vieram juntas no "pacote". Exemplos são o alto índice da saída de jovens do campo para a cidade em busca de trabalho, impactando diretamente no aumento dos sub e desemprego; interesses e ações de bancos, indústrias e multinacionais ligados à acordos com instituições públicas; a "necessidade" de eliminar o excesso de produção de alimentos - enquanto muitos ainda morrem de fome - para regular preços do mercado, dentre outras tantas (Possenti et al., 2007).

Por isso, ao abordar a temática, Rigotto (2010, p.1) coloca que:

Os agrotóxicos não podem ser vistos apenas como um conjunto de substâncias químicas que podem causar riscos químicos à saúde. Eles precisam ser entendidos no contexto em que são utilizados, que envolve o processo de modernização agrícola conservadora em curso no Brasil, que tem a ver com a reestruturação produtiva no campo e a divisão internacional da produção e do trabalho, na qual cabe ao Brasil a produção de commodities de origem agrícola.

Como colocado por Cardoso (2005), o Brasil tem profundas marcas oriundas de seu processo de colonização. Marcas estas que influenciam diretamente na constituição do indivíduo, no modo com que se posiciona no mundo, em especial na escolha do que seria um conhecimento válido (Santos, 2005). Por essa lógica, ao naturalizarmos determinadas práticas, como no caso da estrutura envolvida na produção de alimentos, corre-se o risco de nos tornarmos "cavadores da própria cova", ao passo que se compra o alimento que foi "envenenado" pela mesma indústria que produz seu "antídoto".

Uma vez que esgotar as implicações e relações da dimensão econômica dos agrotóxicos transcende o escopo do presente trabalho, destacamos que estas são apenas algumas questões que podem desencadear debates e novas problemáticas durante a discussão do tema em sala de aula, permeando diferentes disciplinas. Para nos auxiliar na compreensão da teia de conhecimentos envolvida nesta temática, a seguir são discutidas duas, entre muitas, das suas dimensões.

\section{b) Meio ambiente e saúde pública}

O uso indiscriminado de agrotóxicos causa danos tanto à saúde humana quanto aos ecossistemas naturais. Segundo Veiga (2007), os agrotóxicos, por possuírem uma 
variedade de substâncias químicas ou produtos biológicos biocidas, representam um risco em potencial para todos os organismos vivos. Com relação ao ser humano, por exemplo, Rigotto, Vasconcelos e Rocha (2014) afirmam que o uso de agrotóxicos constitui um problema de saúde pública, expondo trabalhadores de fábricas de agrotóxicos, agricultores, moradores próximos das áreas de produção dessas substâncias e de áreas agrícolas, e consumidores de alimentos contaminados.

$\mathrm{Na}$ saúde humana, os efeitos dos agrotóxicos incluem as intoxicações agudas, cujos sintomas surgem rapidamente e que incluem: dores de cabeça, fraqueza, mal-estar, dor de estômago, sonolência, etc., assim como as intoxicações crônicas, caracterizadas pelo surgimento de efeitos tardios, muitas vezes difíceis de ser correlacionados com o uso de agrotóxicos, tais como: depressão, anemia, problemas imunológicos, efeitos na reprodução, doenças do fígado e dos rins, doenças respiratórias, cânceres, etc.

Entre os grupos de maior risco de intoxicação encontram-se os trabalhadores do campo. Segundo o Centro Colaborador de Vigilância em Acidentes de Trabalho, entre 2007 e 2011 houve um aumento de 126,77\% de intoxicações em trabalhadores do setor agropecuário (UFBA, 2012). Entre os 4656 casos de intoxicação por agrotóxicos de uso agrícola (9928 de agrotóxicos em geral) registrados em 2012 pelo SINITOX (Sistema Nacional de Informações Tóxico Farmacológicas) 25,17\% são de cunho ocupacional (SINITOX, 2016). Além disso, há indicativos de índices ainda maiores, devido à dificuldade de registros e diagnósticos.

Segundo Oliveira-Silva et al. (2001):

Em geral, essas conseqüências são condicionadas por fatores intrinsecamente relacionados, tais como o uso inadequado dessas substâncias, a alta toxicidade de certos produtos, a falta de utilização de equipamentos de proteção e a precariedade dos mecanismos de vigilância. Esse quadro é agravado pelo baixo nível socioeconômico e cultural da grande maioria desses trabalhadores (p. 131 e 132).

Entretanto, tal posicionamento requer cautela, visto que, culpabiliza e responsabiliza, de certa forma, os trabalhadores pela contaminação, quando o uso dos agrotóxicos e suas implicações envolve uma gama de aspectos políticos, econômicos e sociais. Além disso, vale salientar o trabalho de Faria, Facchini, Fassa e Tomasi (2004) que, ao construir um perfil da exposição aos agrotóxicos entre trabalhadores do campo da Serra Gaúcha, identificaram que escolaridade, acesso a orientações técnicas e demais indicadores econômicos e agrícolas não estiveram associados aos casos intoxicação.

Além disso, o uso massivo de agrotóxicos tem contaminado alimentos, água, ar e provocado efeitos também na vida animal, alterando ecossistemas (Carneiro et al., 2015; Londres, 2011). Por exemplo, em análise de resíduos de agrotóxicos em alimentos realizada pela Anvisa (Agência Nacional de Vigilância Sanitária) 25\% das amostras apresentavam resíduos acima do tolerado pela agência e $42 \%$ das amostras satisfatórias continham resíduos. Embora o risco para os consumidores tenha sido considerado aceitável, a Anvisa não descarta totalmente o risco à saúde, visto que uma análise mais complexa deve considerar a exposição cumulativa de agrotóxicos com mesmo mecanismo 
de ação, as diversas formas de exposição a um agrotóxico, tais como, exposição pela pele e ingestão de outros alimentos não monitorados como água potável, carnes, leite e ovos, bem como a exposição simultânea a diversas substâncias (Anvisa, 2012).

No que concerne às implicações ambientais, estudos têm investigado e evidenciado inúmeros casos de contaminação, tal como a contaminação de agrotóxicos em água, ar, fauna, chuva e leite materno no município de Lucas do Rio Verde-MT e muitos outros reunidos em Carneiro et al. (2015). Nesse sentido, Londres (2011) enfatiza o conceito de "deriva técnica", que indica a dispersão de agrotóxicos no meio ambiente através do vento ou das águas. Isto é, as substâncias utilizadas no agronegócio não atingem apenas o alvo, mas também contamina o entorno, ainda que todas as normas técnicas sejam seguidas (Londres, 2011).

Segundo estudo da EMBRAPA, que analisou a contaminação do solo e da água por agrotóxicos entre 1992 e 2011 a partir de dados da literatura, resíduos são frequentemente encontrados nos escassos monitoramentos realizados (Gomez, \& Barizon, 2014). Na visão dos autores, embora na maioria dos casos, as concentrações encontradas não apresentem valores críticos, questiona-se a necessidade de estabelecer padrões aceitáveis ao se tratar resíduos químicos. Sobre este aspecto, para Rigotto (2010) o uso seguro de agrotóxicos constitui um mito, isto é:

o conhecimento sobre a nocividade dos agrotóxicos está dado a priori, porque ao defini-los como agrotóxicos estamos dizendo que são biocidas, que fulminam a vida, $\mathrm{e}$ ao atribuir a eles uma classificação toxicológica que vai de pouco tóxico a extremamente tóxico também estamos deixando isso claro. Não há nenhuma classificação que seja 'não-tóxico' (Rigotto, 2010, pp. 2-3).

A partir das informações sucintamente apresentadas, percebe-se o quanto esta dimensão é complexa e, consequente, a importância de reconhecer tal aspecto para a construção de um posicionamento acerca do uso de agrotóxicos.

\section{c) Políticas públicas e participação social}

Segundo Carneiro et al. (2015), dos cinquenta agrotóxicos mais utilizados nas lavouras brasileiras vinte e dois são proibidos na União Europeia. De acordo com Londres (2011), pelo menos dez também são proscritos nos Estados Unidos, China e outros países. Paralelo a este cenário há, ainda, o uso de produtos autorizados para uma específica cultura sendo utilizados em outras e o uso de produtos já proibidos utilizados ilegalmente, mediante contrabando (Londres, 2011).

Apesar dos dados alarmantes, deve-se destacar que existe uma legislação nacional, assim como órgãos de controle, que regulamentam o registro de substâncias, compra e venda, devolução de embalagens, propagandas comerciais, pulverização etc., a qual se fosse devidamente cumprida por todos os atores envolvidos minimizaria consideravelmente os danos (Londres, 2011). A esse respeito, os órgãos reguladores indicam que a maior parte dos alimentos cultivados e vendidos no Brasil violam as regulamentações (Prada, 2015). 
Conhecer os mecanismos reguladores pode contribuir com o envolvimento da população no auxílio da fiscalização. Contudo, deve-se salientar a relevância de um papel mais incisivo do poder público neste processo. Por exemplo, a chefe de toxicologia da Anvisa, órgão federal responsável pela avaliação de riscos dos agrotóxicos à saúde, enfatiza, em reportagem realizada em 2015, a ausência de órgãos e recursos para atender a demanda de produtos que os produtores rurais desejam utilizar (Prada, 2015). Nesse sentido, Prada (2015) complementa que, além das limitações de pessoal, as ações de fabricantes e oposição de legisladores constituem entraves nas avaliações realizadas, estendendo-as para além do prazo estabelecido por lei.

Além dos entraves burocráticos, há também ressalvas quanto às atividades legisladoras no país a esse respeito. Um exemplo interessante consiste no monitoramento de resíduos de agrotóxicos na água. Segundo Carneiro et al. (2015), este é um tema pouco pesquisado e com escassez de dados oficiais para consulta. Além disso, os autores destacam que, analisando as portarias que regulamentam os parâmetros de potabilidade da água brasileira, verifica-se um aumento das substâncias permitidas, o que pode ser considerado reflexo da crescente poluição do processo produtivo industrial, do processo agrícola e do processo de desinfecção doméstica.

Também sobre o papel das políticas públicas nesse processo, Soares, Almeida e Moro (2003) enfatizam "a necessidade de que a informação sobre os riscos do uso inadequado de agrotóxico seja adequadamente incorporada a políticas públicas de prevenção e saúde do trabalhador rural" (p. 1127).

Apesar das discussões acerca de uma maior fiscalização do uso de agrotóxicos em parceria com a população, segundo Carneiro et al. (2015) o debate tem sido ampliado, abarcando o seu banimento e a criação de políticas e alternativas ao seu uso, com a instituição de mecanismos de produção de alimentos agrosustentáveis (agroecologia).

É importante salientar que as opções por práticas de cultivos convencionais estão relacionadas com o modelo socioeconômico adotado no país, tal como explicitado anteriormente no item sobre a dimensão econômica. Nesse sentido, Lindemann (2010) questiona os critérios para se julgar e parametrizar a forma mais viável de produção de alimentos, para a autora:

Se os agricultores têm clareza dos principais pontos, por exemplo, conservação do ambiente, da equidade social, do custo-benefício, etc., o "dar certo" [da técnica de plantio] tem uma dimensão diferente de outros experimentos balizados exclusivamente pela maximização da produção. Transformar tem implicações, comporta escolhas, e essas se fazem com sujeitos conscientes, também nos processos de produção agrícola (Lindemann, 2010, p. 230).

Nesse sentido, Seufert, Ramankutty e Foley (2012), ao comparar os rendimentos de manejos agrícolas orgânicos e convencionais, além de argumentar que as diferenças produtivas entre as duas técnicas dependem do contexto de produção e, em alguns casos, podem até ser correspondentes, salientaram que "os rendimentos são apenas uma parte de uma série de fatores econômicos, sociais e ambientais que devem ser considerados 
ao avaliar os benefícios de diferentes sistemas de produção" (p. 231). Além disso, os autores argumentam que a discussão deve ultrapassar a polarização "orgânico versus convencional", englobando a avaliação dos custos e benefícios de diferentes opções de manejo, inclusive, técnicas híbridas (orgânicos e convencionais).

Diante deste cenário, organizações e membros da sociedade civil têm organizado iniciativas tendo em vista a mudança dos modelos de produção adotados no Brasil. Como exemplo, pode-se mencionar a Campanha Permanente Contra os Agrotóxicos e pela Vida, a qual, composta por um coletivo que inclui movimentos sociais, universidades e instituições de pesquisa, movimentos sindicais, entidades, movimentos estudantis, integrantes do setor legislativo do país, entre outros, se opõe ao uso crescente de agrotóxicos no país. Iniciativas como esta buscam alertar a população para os prejuízos ocasionados pelo modelo de produção agrícola nacional, os quais abarcam, por exemplo, a marginalização da agricultura familiar, a perda de biodiversidade e a contaminação ambiental, e intoxicação, como evidencia o "Dossiê ABRASCO: um alerta sobre os impactos dos agrotóxicos na saúde".

A partir das considerações apresentadas nesta seção sobre os aspectos econômicos, ambientais e sociais do uso de agrotóxicos no Brasil foi sistematizada uma rede de relações, baseada na proposta da Rede Temática (Silva, 2004), com a finalidade de evidenciar a malha sociocultural na qual a temática dos agrotóxicos encontra-se imersa, tal como pode ser visualizado na Figura 1 a seguir.

Com base em Silva (2004), a Figura 1 deve ser lida de baixo para cima, ou seja, partindo da "dimensão local", representada por dados fornecidos pela literatura, para a dimensão macroestrutural, que se refere aos diferentes fatores associados aos aspectos econômicos, ambientais e de saúde pública, e relacionados com as políticas públicas e participação social. Como já colocado, no presente trabalho foram utilizados dados extraídos de estudos acadêmicos para representar a dimensão local, tendo em vista o uso da rede como instrumento analítico. Entretanto, em abordagens freireanas, é imprescindível que a dimensão local seja constituída por falas representativas de uma comunidade escolar específica. Compreende-se que a rede de relações apresentada na Figura 1, assim como as discussões aqui apresentadas, pode auxiliar professores e pesquisadores em Educação em Ciências na abordagem desta temática. 


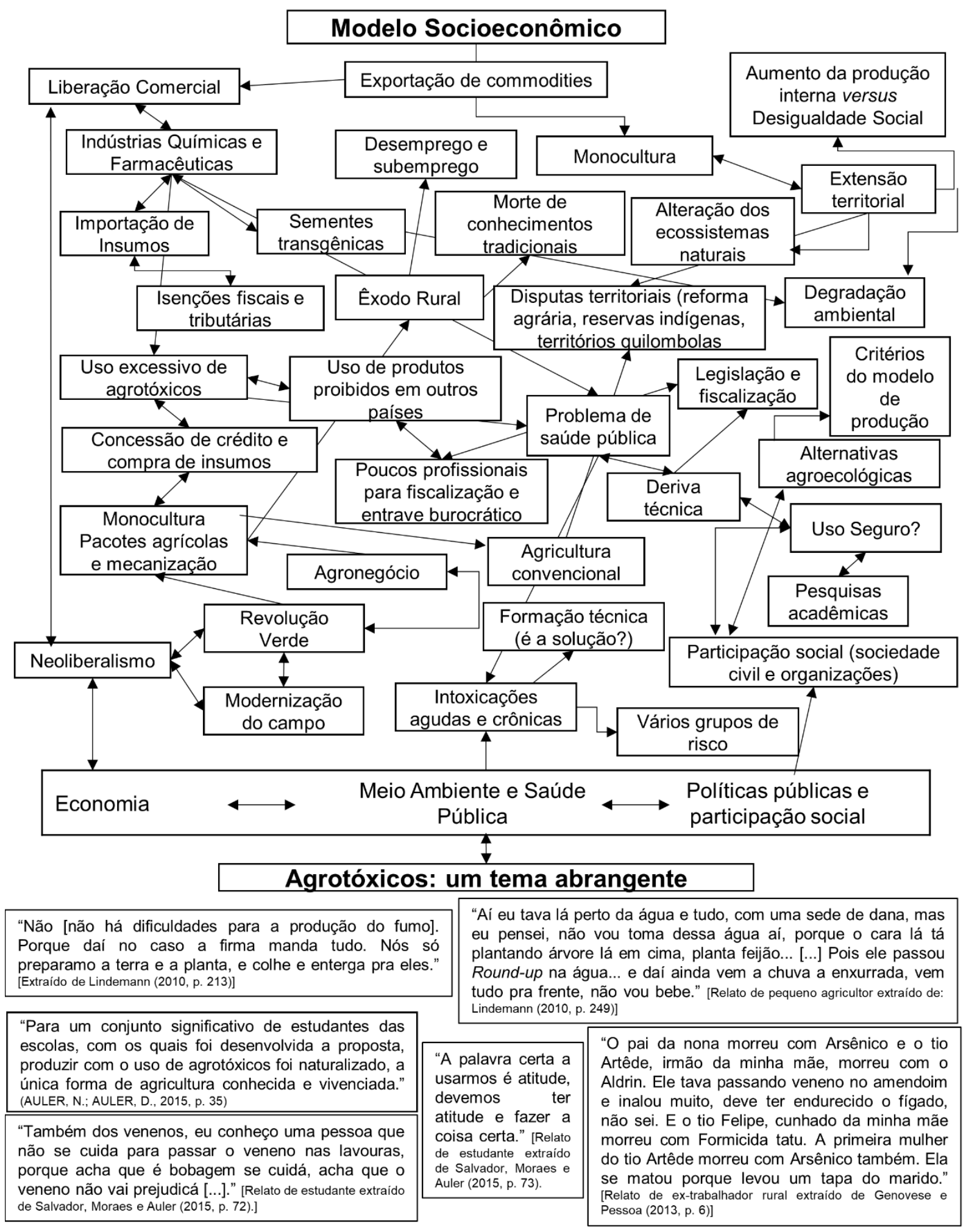

Figura 1. Rede de relações sobre o uso de agrotóxicos no Brasil elaborada pelas autoras com base na Rede Temática (Silva, 2004) 


\section{Considerações e implicações}

Conforme apresentado, a abordagem do tema "Agrotóxicos" em sala de aula necessita considerar o seu caráter social e científico controverso, isto é, os diferentes posicionamentos sobre vários aspectos envolvidos em sua discussão, tendo em vista auxiliar os educandos na construção de uma percepção mais ampla da realidade para que possam, sobre ela, se posicionar e intervir. Entretanto, o caráter controverso do tema pode dificultar a sua abordagem em sala de aula, uma vez que envolve aspectos de ordem conceitual, social, econômica, política, de saúde pública, ambiental e segurança alimentar. Sob este prisma, compreende-se que as discussões apresentadas no presente trabalho e sistematizadas na rede de relações podem contribuir com a educação em Ciências ao auxiliar professores e pesquisadores na discussão e abordagem da problemática dos agrotóxicos em diferentes espaços formativos, apresentando o potencial para serem utilizadas, inclusive, como material de apoio na formação de professores.-

Como discutido anteriormente, a instituição da agricultura convencional que conhecemos hoje vem desencadeando ações que impactam, de maneira negativa, em diversas áreas da vida. Como visto, a maioria das pesquisas que discutem problemáticas relacionadas com o uso de agrotóxicos na área de ensino de ciências enfatizam as relações entre os agrotóxicos e conteúdos científicos, seus impactos no ambiente, como ser letrado de maneira que possa compreender embalagens e utilizar de maneira adequada seus devidos equipamentos de proteção. Silenciando, assim, outros aspectos, tal como a dimensão econômica que, quando abordada, enfatiza apenas os números e estatísticas que correlacionam a produtividade ao agrotóxico.

Neste trabalho defendemos que uma compreensão mais ampla do tema agrotóxico, tal como exemplificada ao longo do texto e sistematizada na rede de relações (Figura 1), pode contribuir com a estruturação de atividades nas quais os conhecimentos científicos se tornem instrumentos para uma leitura crítica da realidade, aspecto preconizado por articulações Freire-CTS. Ainda que os elementos aqui apresentados constituam um recorte das discussões sobre o uso de agrotóxicos no Brasil, contribuem para a visualização da malha sociocultural em que está imbricado, evidenciando o potencial do desenvolvimento de temas CTS em uma perspectiva freireana. Afinal, capacitar os educandos para a tomada de decisão num contexto social marcado pela Ciência e Tecnologia, tal como sinalizado pelo movimento CTS (Santos, 2011), perpassa considerar, não apenas os conhecimentos das ciências naturais envolvidos, mas também a dimensão histórico-social do tema em questão, articulação presente em abordagens freireanas.

Com a discussão apresentada, advogamos em prol da apropriação de alguns elementos essenciais para a discussão do uso de agrotóxicos no Brasil em sala de aula, que possam amenizar o risco de adotar uma postura simplista ou endossar o modelo tecnocrático. Sobre este aspecto, enfatizamos a importância da construção de redes vinculadas ao contexto de atuação dos professores e/ou pesquisadores, isto é, a importância da base da rede ser constituída por falas significativas da comunidade 
local, de possibilitar a interlocução entre diferentes áreas e saberes nesse processo mediante o desenvolvimento do processo de Investigação Temática, aspecto que demanda investigações futuras. Nesse sentido, considerando as condições de trabalho dos docentes da educação básica e, por conseguinte, a dificuldade de estabelecer práticas interdisciplinares e coletivas nas escolas, sinalizamos que a formação de grupos colaborativos constituídos por integrantes da comunidade acadêmica e escolar apresentase como uma alternativa viável no enfrentamento destes desafios e para a aproximação entre pesquisa e ensino (Sousa, Solino, Figueiredo, \& Gehlen, 2016).

Ademais, salientamos que, mais do que um diagrama, a rede de relações apresentada constitui um instrumento analítico-propositivo, pautado em uma concepção educacional ético-crítica, cuja leitura/análise, assim como a sua construção, requer um processo educativo (Silva, 2004). Em outras palavras, compreender tal rede envolve considerar as discussões que desencadearam a sua construção e, da mesma forma, construí-la perpassa a formação dos sujeitos envolvidos, razão pela qual enfatizamos o potencial da rede de relações apresentada tanto para possibilitar uma abordagem mais ampla da temática dos agrotóxicos em sala de aula, quanto para a formação de professores, em particular, quando mediante a sua construção considerando as especificidades do tema no contexto escolar.

\section{Referências}

Angotti, J. A. P. (1991). Fragmentos e totalidades no conhecimento científico e no ensino de ciências. Tese de doutorado, Universidade de São Paulo, São Paulo-SP, Brasil.

ANVISA - Agência Nacional de Vigilância Sanitária. (2012). Relatório Complementar. Recuperado de http://portal.anvisa.gov.br/documents/111215/117818/ PARA\%2BResultados2012B_Resumido-14-11-14.pdf/cb191ff1-b908-44b8-8a73a8f55177f72a

Aranha, A., \& Rocha, L. (2019). “Coquetel” com 27 agrotóxicos foi achado na água de 1 em cada 4 municípios. Por trás do alimento. Recuperado de: https://portrasdoalimento. info/2019/04/15/coquetel-com-27-agrotoxicos-foi-achado-na-agua-de-1-em-cada-4municipios/

Auler, D. (2002). Interações entre Ciência-Tecnologia-Sociedade no Contexto da Formação de Professores de Ciências. Tese de doutorado, Universidade Federal de Santa Catarina, Florianópolis-SC, Brasil.

Auler, D. (2007). Enfoque Ciência-Tecnologia-Sociedade: pressupostos para o contexto brasileiro. Ciência \& Ensino, 1(número especial), 1-20.

Auler, D. (2011). Novos caminhos para a educação CTS: ampliando a participação. In W. L. P. Santos, \& D., Auler (Orgs.). CTS e educação científica: desafios, tendências e resultados de pesquisas (pp. 73-98). Brasília: Editora Universidade de Brasília. 
Auler, N. M. F., \& Auler, D. (2015). Conhecer e executar currículos: ampliando o processo formativo de educadores(as). In Auler, N. M. F., \& Auler, D. (Orgs.). Concepção e execução do currículo no processo formativo de Licenciandos do PIBID (pp. 13-40) Curitiba: CRV. Auler, D., Dalmolin, A., \& Fenalti, V. (2009). Abordagem temática: natureza dos temas em Freire e no enfoque CTS. Alexandria - Revista de Educação em Ciência e Tecnologia, $2(1), 67-84$.

Bazzo, W., Linsingen, I., \& Pereira, L. T. do V. (2003). Introdução aos estudos CTS (Ciência, Tecnologia e Sociedade). Cadernos de Ibero-América. Madri: Organização dos Estados Ibero-americanos para a Educação, a Ciência e a Cultura.

Bianchini, V., \& Medaets, J. P. P. (2013). Da revolução verde à agroecologia: plano Brasil agroecológico. Recuperado de http://www.mda.gov.br/portalmda/sites/default/files/ user_arquivos_195/Brasil\%20Agroecol\%C3\%B3gico\%2027-11-13\%20Artigo\%20 Bianchini\%20e\%20Jean\%20Pierre.pdf

Calvão, A. L. (2017). O homem do campo e as questões ambientais: culturas tradicionais $\mathrm{x}$ revolução verde - suas mazelas e as alternativas possíveis. Sinapse Múltipla [online], 6(1), 82-89.

Carneiro, F. F., Augusto, L. G. S., Rigotto, R. M., Friedrich, K., \& Búrigo, A. C. (Org.). (2015). Dossiê ABRASCO: um alerta sobre os impactos dos agrotóxicos na saúde. Rio de Janeiro: EPSJV; São Paulo: Expressão Popular.

Cavalcanti, J. A., Freitas, J. C. R., Melo, A. C. N., \& Freitas, J. R. (2010, fevereiro) Agrotóxicos: uma temática para o ensino de química. Química Nova Escola, 32 (1), 3136.

Delizoicov, D. (1991). Conhecimento, tensões e transições. Tese de doutorado, Universidade de São Paulo, São Paulo-SP, Brasil.

Delizoicov, D., Zanetic, J. (1993). A proposta de interdisciplinaridade e o seu impacto no ensino municipal de $1^{\circ}$ grau. In N. N., Pontuschka, (Org.). Ousadia no diálogo: a interdisciplinaridade na escola pública (pp. 9-15). São Paulo: Loyola.

Faria, N. M. X., Facchini, L. A., Fassa, A. G., \& Tomasi, E. (2004, set-out.). Trabalho rural e intoxicações por agrotóxicos. Cad. Saúde Pública, Rio de Janeiro-RJ, 20 (5), 1298-1308.

Felipim, A. P. (2001). O Sistema Agrícola Guarani Mbyá e seus cultivares de milho: um estudo de caso na Aldeia Guarani da Ilha do Cardoso, município de Cananéia, SP. Dissertação de Mestrado, Universidade de São Paulo, Piracicapa-SP, Brasil.

Fernandes, C. S., \& Stuani, G. M. (2015). Agrotóxicos no Ensino de Ciências: uma pesquisa na educação do campo. Educação e Realidade, Porto Alegre-RS, 40(3), 745-762.

Freire, P. (1983). Extensão ou Comunicação? 8a ed. Rio de Janeiro: Paz e Terra.

Freire, P. (2011). Pedagogia do Oprimido. 50a ed. Rio de Janeiro: Paz e Terra. 
Genovese, C. L. C. R., \& Pessoa, J. M. (2013). Trabalhador Rural, Agrotóxicos e Ensino de Ciências: uma análise. In Atas do IX Encontro Nacional de Pesquisa em Educação em Ciências, Águas de Lindóia-SP, Brasil.

Gomes, M. A. F., \& Barizon, R. R. M. (2014). Panorama da contaminação ambiental por agrotóxicos e nitrato de origem agrícola no Brasil: cenário 1992/2011. Jaguariúna, SP: Embrapa Meio Ambiente.

Hue, S. M. (Org.) (2006). Primeiras Cartas do Brasil (1551-1555). Rio de Janeiro: J. Zahar. Lerrer, D. F. (2019). Mecanismos de silenciamento do problema agrário brasileiro: reflexões preliminares. In Anais VIII Encontro da Rede de Estudos Rurais Concepções de Sociedade e Direitos de Cidadania em Questão: novos desafios para o mundo rural brasileiro. Rede de Estudos Rurais, Florianópolis - SC, Brasil.

Lindemann, R. H. (2010). Ensino de Química em escolas do campo com proposta agroecológica: contribuições a partir da perspectiva freireana de educação. Tese de Doutorado. PPGECT: UFSC, Florianópolis-SC, Brasil.

Londres, F. (2011). Agrotóxicos no Brasil: um guia para ação em defesa da vida. - Rio de Janeiro: AS-PTA - Assessoria e Serviços a Projetos em Agricultura Alternativa.

Lopes, N. C., \& Carvalho, W. L. P. (2012, jul-dez). Agrotóxicos - toxidade versus custos: uma experiência de formação de professores com as questões sociocientíficas no ensino de ciências. Amazônia - Revista de Educação em Ciências e Matemáticas, 9(17), 27-48.

Miranda, A. C., Moreira, J. C., Carvalho, R., \& Peres, F. (2007). Neoliberalismo, uso de agrotóxicos e a crise da soberania alimentar no Brasil. Ciência e saúde coletiva [online]. 12(1), 7-14.

Moraes, P. C., Trajano, C. S., Mafra, S. M., \& Messede J. C. (2011), Abordando agrotóxico no ensino de química: uma revisão. Revista ciências \& ideias, 3(1), 1-15.

Nascimento, T. G., \& Linsingen, I. (2006). Articulações entre o enfoque CTS e a pedagogia de Paulo Freire como base para o ensino de ciências. Convergência, 13(42), 95-116.

Oliveira-Silva, J. J., Alves, S. R., Meyer, A., Perez, F., Sarcinelli, P. N., Mattos, R. C. O.C., \& Moreira, J. C. (2001). Influência de fatores socioeconômicos na contaminação por agrotóxicos, Brasil. Revista de Saúde Pública, 35(2), 130-135.

Pernambuco, M. M. C. (1994). Educação e escola como movimento. Tese de doutorado Universidade de São Paulo, São Paulo-SP, Brasil.

Possenti, J. C., Tozetto, F. C., Bettiato, G., \& Szepanhuk V. (2007). A agricultura convencional e suas implicações para o meio ambiente. In I Seminário Sistemas de Produção Agropecuária. Universidade Tecnológica Federal do Paraná - Campus Dois Vizinhos.

Prada, P. (2015). Why Brazil has a big appetite for risky pesticides, Recuperado de: http:// www.reuters.com/investigates/special-report/brazil-pesticides/ 
Prado Júnior, C. (1949). História econômica do Brasil. 2 ed. São Paulo: Brasiliense.

Reis, P. R. (2004). Controvérsias sócio-científicas: discutir ou não discutir?: percursos de aprendizagem na disciplina de ciências da terra e da vida. Tese de doutorado - Faculdade de Ciências da Universidade de Lisboa, Lisboa, Portugal.

Reuters. (2019). Ministério da Agricultura aprova registro de mais 42 agrotóxicos, totalizando 211 no ano. G1 - Globo. Recuperado de https://g1.globo.com/economia/ agronegocios/noticia/2019/06/24/ministerio-da-agricultura-aprova-registro-de-mais42-agrotoxicos-totalizando-211-no-ano.ghtml

Rigotto, R. (2010). O uso seguro de agrotóxicos é um mito: depoimento [22 de setembro de 2010]. EPSJV\Fiocruz. Entrevista concedida a Leila Leal. Recuperado de http://www. epsjv.fiocruz.br/noticias/entrevista/o-uso-seguro-de-agrotoxicos-e-um-mito

Rigotto, R. M., Vasconcelos, D. P., \& Rocha, M. M. (2014). Uso de agrotóxicos no Brasil e problemas para a saúde pública. Cad. Saúde Pública, Rio de janeiro, 30(7), 1-3.

Romeiro, A. R. (1996). Agricultura Sustentável, Tecnologia e Desenvolvimento Rural. Agricultura Sustentável, Jaguariúna, 3(1/2), 34-42.

Salvador, C. H., Moraes, T. O., \& Auler, N. M. F. (2015). Intervenção curricular estruturada mediante um tema gerador. In Auler, N. M. F., \& Auler. D. (Orgs.). Concepção e execução do currículo no processo formativo de Licenciandos do PIBID (63-76). Curitiba: CRV.

Santos, B. S. (2005). Semear outras soluções: os caminhos da biodiversidade e dos conhecimentos rivais. Rio de Janeiro: Civilização Brasileira.

Santos, W. (2011). Significados da educação científica com enfoque CTS. In W., Santos, \& D., Auler (Orgs.) CTS e educação científica: desafios, tendências e resultados de pesquisa (pp. 21-48). Brasília: Editora UnB.

Santos, W. L. P., \& Mortimer, E. F. (2002). Uma análise de pressupostos teóricos da abordagem C-T-S (Ciência-Tecnologia-Sociedade) no contexto da educação brasileira. Ensaio - Pesquisa em Educação em Ciências, 2(2), 1-22.

Schwartzman, S. (1989). A Ciência no período de pós-guerra. In II Módulo do Programa de Política e Administração em Ciência e Tecnologia, CNPq, 1989. Recuperado de: http:// www.schwartzman.org.br/simon/posguerr.htm

Seufert, V., Ramankutty, N., \& Foley, J. A. (2012). Comparing the yields of organic and conventional agriculture. Nature, 485, 229-232.

Silva, A. F. G. (2004). Das falas significativas às práticas contextualizadas: a construção do currículo na perspectiva crítica e popular. Tese de doutorado - Pontifícia Universidade de São Paulo, São Paulo-SP, Brasil.

Silva, A. F. G. (2007). A busca do tema gerador na práxis da educação popular. Curitiba: Editora Gráfica Popular. 
SINITOX - Sistema Nacional De Informações Tóxico-Farmacológicas. (2016). Dados de Intoxicação. Recuperado de http://sinitox.icict.fiocruz.br/dados-nacionais

Soares, W., Almeida, R. M.V. R., \& Moro, S. (2003). Trabalho rural e fatores de risco associados ao regime de uso de agrotóxicos em Minhas Gerais, Brasil. Cad. Saúde Pública, Rio de Janeiro, 19(4), 1117-1127.

Sousa, P. S., Solino, A. P., Figueiredo, P. S., \& Gehlen, S. T. (2016). Tema Gerador e a Relação Universidade-Escola: Percepções de Professoras de Ciências de uma Escola Pública em Ilhéus-BA. Alexandria-Revista de Educação em Ciência e Tecnologia, 9(1), $3-29$.

Strieder, R. B. (2012). Abordagens CTS na Educação Científica no Brasil: sentidos e perspectivas. Tese de doutorado - Universidade de São Paulo, São Paulo-SP, Brasil.

Takahashi, J. A., Martins, P. F. F., \& Quadros, A. L. (2008). Questões tecnológicas permeando o ensino de química: o caso dos transgênicos. Química nova na escola, 29, $3-7$.

UFBA - Universidade Federal da Bahia. (2012). Acidentes de trabalho devido à intoxicação por agrotóxicos entre trabalhadores da agropecuária 2000-2011. Salvador: Centro Colaborador de Vigilância em Acidentes de Trabalho, Universidade Federal da Bahia.

Veiga, M. M. (2007). Agrotóxicos: eficiência econômica e injustiça socioambiental. Ciência \& Saúde Coletiva, 12(1), 145-152.

Linsingen, I. (2007). Perspectiva educacional CTS: aspectos de um campo em consolidação na América Latina. Ciência \& Ensino, 1(número especial).

Watson, A. S. G. (2016). O Brasil e as restrições às exportações. Brasília: FUNAG. 
Polliane Santos de Sousa

(ㄷ) https://orcid.org/0000-0001-5853-0352 Universidade Federal do Recôncavo da Bahia

Centro de Formação de Professores Área de Física e Sociedade Amargosa Bahia, Brasil

Universidade Federal de Santa Catarina Programa de Pós-Graduação em Educação Científica e Tecnológica Florianópolis, Santa Catarina, Brasil polliane.sds@gmail.com

\section{Ana Paula Gorri}

(1) https://orcid.org/0000-0003-1335-2956

Universidade Federal de Santa Catarina

Programa de Pós-Graduação em Educação Científica e Tecnológica

Florianópolis, Santa Catarina, Brasil apgorri1@gmail.com

Submetido em 05 de abril de 2019

Aceito em 12 de agosto de 2019

Publicado em 18 de setembro de 2019 